\title{
Proyectos urbanos en disputa: los debates en torno al proyecto de la Alameda en Buenos Aires (1766-1768)
}

\author{
Urban projects in dispute: the debate around the project of the \\ Alameda in Buenos Aires (1766-1768)
}

\section{Betina Laura Sidy ${ }^{2}$}

\section{RESUMEN}

En este trabajo exploraremos en torno a los debates que se suscitaron entre el Cabildo de Buenos Aires y el gobernador Bucareli en relación al proyecto de construcción de la Alameda, con el objetivo de poner en discusión cuáles eran los planteos urbanísticos relevantes para la época y cuáles las necesidades concretas de la ciudad en su funcionamiento cotidiano según cada uno de los actores intervinientes. Dicha disputa cobró características que fueron más allá del juego de influencias económicas planteando cuestionamientos en torno a las formas en que un proyecto urbano y político era conceptualizado a mediados del siglo XVIII.

Palabras claves: Buenos Aires. Siglo XVIII. Alameda. Proyecto urbano. Reformismo borbónico.

\section{ABSTRACT}

In this paper we will explore around the debates raised between the Cabildo of Buenos Aires and

1 Este trabajo es producto de las investigaciones doctorales financiadas por una beca de postgrado otorgada por el CONICET.

2 Doctoranda en Ciencias Antrpológicas en la Facultad de Filosofía y Letras, Universidad de Buenos Aires, becaria del Consejo Nacional de Investigaciones Científicas y Técnicas con lugar de trabajo en el Instituto de Altos Estudios Sociales de la Universidad Nacional de San Martín. Participante del proyecto de investigación UBACyT "Cambio y continuidad en la sociedad hispano-criolla", investiga el crecimiento y las transformaciones en la ciudad de Buenos Aires en el período colonial (1720-1776) a partir de las relaciones entre Políticas de gobierno, sociedad y espacio urbano. 
Governor Bucareli in relation to the proposed construction of the Alameda, in order to call into question what were the urban proposals relevant to the time and what the specific needs of the city in their daily functioning according to each of the actors involved. This dispute took on features that went beyond the game of economic influences raising questions concerning the forms in which an urban and political project was conceptualized in the mid-eighteenth century.

Keyword: Buenos Aires. Eighteenth Century. Alameda. Urban Project. Bourbon Reformism.

\section{Introducción}

Entre los años 1767 y 1770 se desarrolló en la ciudad de Buenos Aires un conflicto entre algunos miembros del Cabildo y el gobernador Don Francisco de Paula Bucareli y Ursúa. El mismo, tuvo como eje la realización ciertas obras públicas que incluían el allanamiento de las calles aledañas al río desde el fuerte para la edificación de un paseo público. Aparentemente, todo comenzó cuando el gobernador llegó a Buenos Aires en 1766 y tuvo la intención de realizar un paseo en coche por la costa del Río de la Plata desde el fuerte. Sin embargo, le advirtieron que no existía, hasta el momento, ninguna calzada por la cual acceder de ese modo. Frente a estos inconvenientes, y habiendo consultado con el ingeniero Don Juan Bartolomé Hovell se idearon los obras necesarias para facilitar el camino hacia el río -que hasta el momento concluía en barrancas.

Ya en 1757, el Cabildo había desestimado por falta de propios, la propuesta del gobernador Cevallos para realizar obras similares en la ciudad (AECBAa, 1930, p. 178-181). Sin embargo con la llegada de Bucareli al Río de la Plata a medidos de 1766, las llamadas obras públicas cobran impulso amparadas en la férrea decisión del funcionario borbónico de llevarlas a cabo. Para ello, decide implementar un derecho sobre las cuadras del ejido que el Rey había otorgado por real cédula a la ciudad en 1760 para finalizar las casas capitulares y liquidar sus deudas 3 . Frente a estas intenciones de parte del gobernador, se producen, al interior del Cabildo, largos debates entre aquellos que estaban a favor de la propuesta y aquellos que no. Si bien no cuestionamos la posibilidad de que la raíz del conflicto estuviera vinculada a las capacidades de especulación política y comercial de algunas de las

3 Vale aclarar, de dónde surge este derecho otorgado al Cabildo. En el planteo urbano colonial, el ejido consistía, a diferencia de la traza, en un amplio terreno que debía conservarse libre de ocupación destinado a zona de pastoreo, constituyendo así la única tierra disponible ante la presión demográfica que se produjo a inicios del siglo XVIII. El proceso de ocupación del ejido se inició en 1720 cuando el Cabildo comenzó a ceder porciones a distintos pobladores y creció de manera vertiginosa hasta que por 1734 el alcalde de hermandad denunció estos hechos ante el gobernador. Se abrió un proceso judicial en el que se dirimió, la potestad del Cabildo para ceder tierras así como el destino que corría el modelo de ciudad regular. Este conflicto culminó en 1760 cuando la corona aceptó la ocupación del ejido como un hecho consumado y otorgó al Cabildo el derecho al cobro de un impuesto a sus ocupantes (FAVELUKES, 2006). Este derecho sobre el que van a girar las controversias con el gobernador- había sido otorgado, a través de una cédula real por Su Majestad en 1760 con el objetivo preciso de finalizar las casas capitulares y liquidar las deudas de la ciudad. Sin embargo para 1768 el impuesto aún no se había implementado porque no se habían terminado las tareas de mensura del ejido. Ver: (DOC Y PLANOS, 1910, p. 137; AECBAb, 1927, p. 478-480, p.497-501). 
personalidades más importantes del Buenos Aires colonial, (teniendo en cuenta que entre los defensores se encontraban las familias más poderosas de la ciudad, por ejemplo los Basavilbaso y los Lezica ${ }^{4}$ ), en particular en lo que refiere al manejo de los fondos recaudados, observamos que la disputa cobró características que fueron más allá del juego de posiciones e influencias económicas, y que nos plantean cuestionamientos en torno a las variadas formas en que un proyecto urbano era conceptualizado.

En este trabajo nos proponemos explorar en torno a estos debates para poner en discusión cuáles eran los planteos urbanísticos relevantes para la época y cuáles las necesidades concretas de la ciudad en su funcionamiento cotidiano según cada uno de los actores intervinientes. En particular nos proponemos, a partir de este caso concreto, indagar acerca de la capacidad de los idearios borbónicos urbanos, de matriz neoclásica, para transformar los espacios de las ciudades coloniales latinoamericanas. El estilo neoclásico dependiente del iluminismo proponía - a diferencia del barroco predominante en la épocaque la devoción fuera experimentada como un fenómeno interno y privado en lugar de externo y público, así como también la implementación de una cierta racionalidad en el espacio que permitiese la circulación fluida de bienes, gente, aire, etc. Se buscaba así favorecer la recolección de los impuestos y el control social y económico, bajo la premisa de limitar la ostentación y lograr un mayor orden (WALKER, 2007) produciéndose a su vez una cierta reorientación desde el gobierno del ocio y de la recreación que evitara el desarrollo de conflictos sociales (PEREZ CANTO, 1985).

Existen pocos trabajos que se dediquen al caso de la alameda de Buenos Aires, y en líneas generales se trata de textos de tipo descriptivo, que no ahondan en los conflictos que el mismo suscito entre los responsables del gobierno de la ciudad (SALVADORES, 1931). Sin embargo, numerosos autores han analizado los programas borbónicos tendientes a transformar las ciudades americanas de acuerdo a los nuevos ideales neoclásicos que permitirían, junto con una presencia cada vez mayor de las autoridades reales en las colonias, lograr un mayor control de las personas, de sus actividades en el espacio y de las rentas allí producidas, limitando las características barrocas vigentes en la sociedad (DE SOLANO, 1990; RAMON, 1999; RIPODAS ARDANAZ, 2003; WALKER, 2007). En este sentido se registra -sobre todo a partir de nuevas ordenanzas- una preocupación cada vez mayor por la higiene, la circulación tanto del aire como de los bienes y de las personas y por el cuidado de los servicios de la ciudad: pavimentación, infraestructura, iluminación, apertura de plazas, calles y paseos. Sin embargo, también se ha puesto en duda la efectiva implementación y el alcance real logrado por dichas reformas. Con respecto a las transformaciones físicas de las

4 Por ejemplo, Domingo Basavilbaso - quien oficiara de fiador de Bucareli cuando arribó a Buenos Aires- fue procurador general de la ciudad en 1739. En 1748 tras promover la instalación del correo marítimo en Buenos Aires fue nombrado administrador de correos y postas. Fue mayordomo de la catedral desde 1752, capitán de la milicia local, miembro de la orden tercera de San Francisco y de la Hermandad de la Caridad. Como jefe de uno de los clanes comerciales más importantes de la segunda mitad del siglo XVIII porteño, fue un hombre de mucho poder. Sus hijos (Manuel y Francisco) y yernos (entre los que se destacaron Pascual Ibañez y Vicente de Azcuenaga) lo continuaron, aunque con diferentes grados de éxito. 
ciudades, coincidimos con los planteos de Walker (2007), quien señala que, a la hora de llevar a la práctica los ideales reformistas, la oposición de las fuerzas locales, así como los altos costos que lo mismo implicaba condujeron a una posición ambivalente de parte de la corona española que no siempre logró sostener en la práctica sus planteos originales.

Cabe aclarar, antes de adentrarnos en el caso específico, cuáles eran las características generales de la ciudad de Buenos Aires y el contexto en que estaba inserta al momento de la llegada del gobernador, así como también realizar un breve repaso en relación a los antecedentes de Bucareli, para poder intuir cuáles eran sus principales intereses y preocupaciones.

\section{La ciudad de Buenos Aires a mediados del siglo XVIII}

La ciudad de Buenos Aires se había caracterizado, por ser un puerto precario, de pocas riquezas tanto materiales como humanas que cumplía con una función defensiva, frente a la posibilidad de un avance portugués y/o inglés por el norte del Río de la Plata. Sin embargo, con el correr del 1700 y la llegada de la dinastía borbónica al trono español, el panorama local se fue modificando, junto con el interés cada vez mayor de la corona por reforzar y realzar ciertas áreas periféricas en detrimento de los tradicionales enclaves de poder colonial con el fin de disolver y fragmentar las jerarquías emergentes en el nuevo mundo y someter a sus componentes al control metropolitano (MORSE, 2003).

Así como la ciudad había sido trazada y dividida como forma de control, de intervención, de división de jerarquías, está misma forma de concebir el espacio se transpuso en lo ideológico, a la organización política de todo el sistema colonial. Sin embargo, así como en las ciudades se dieron movimientos particulares que fueron más allá de la filosofía política del momento, este proyecto borbónico de descentralización del poder fue reapropiado y resignificado por los actores que intervinieron en el mismo, produciéndose así un margen entre el ideal metropolitano y la praxis concreta, que fue aprovechado por las autoridades locales para defender la autonomía política a la que estaban acostumbradas y que se veía amenazada por los intereses centralizadores de los funcionarios borbónicos. En esta carrera de transformaciones políticas comenzó un proceso por el cual se produjo un considerable aumento del poder en los centros hasta entonces periféricos, entre los que se encontraba Buenos Aires quien, -más allá de mantener su precaria infraestructura- fue adquiriendo un estatus cada vez mayor en el plano económico y político. ${ }^{5}$ Esto último se evidencia, entre otras cosas, con la designación de Francisco de

5 A partir de la lectura de los bandos de los gobernadores a lo largo del siglo, como de los relatos de los viajeros que pasaron por Buenos Aires conocemos el pobre estado de las calles, las constantes inundaciones que dificultaban el tránsito, la disposición del suelo en distintos niveles que impedía el rápido desagote, la ocupación caótica del ejido que 
Paula Bucareli y Ursúa a cargo del gobierno de la ciudad. Este funcionario, llegó al Río de la Plata con la comisión de ejecutar la expulsión de la Compañía de Jesús en las provincias de Buenos Aires, Paraguay y Tucumán, la medida más significativa dentro de los propósitos borbónicos destinados a restar poder a la Iglesia Católica en las colonias americanas. En este sentido, Bucareli, quien venía de ocupar el cargo de virrey en Mallorca encarnaba un claro representante de los idearios borbónicos, lo que se evidencia en el desarrollo de su gobierno en la ciudad y en los diversos conflictos que entabló, en particular con el Cabildo porteño, frente al cual sistemáticamente intentó imponer su autoridad, al restarle la autonomía con la que tradicionalmente había manejado los asuntos urbanos, despertando así fuertes resistencias de parte de algunos de los miembros de este enclave de poder local. ${ }^{6} \mathrm{El}$ mayor conflicto se desató en torno al interés de parte del gobernador por utilizar un impuesto otorgado por SM para finalizar las casas capitulares y realizar obra pública, (DOC Y PLANOS, 1910, p. 137) con el objetivo de ultimar el allanamiento de las calles que conducían al río y el paseo público denominado Alameda. Este proyecto, estaba en sintonía con el incipiente neoclasicismo que comenzaba a aparecer en Europa y con el interés por embellecer los espacios urbanos, integrar la naturaleza a la ciudad y controlar el ocio de la población (HERNANDO, 1989).

\section{Breve sintesis del conflicto ${ }^{7}$}

Como ya se mencionó, desde su llegada el gobernador observó la necesidad de volver transitable el camino entre el fuerte y el río. En este sentido, convocó al ingeniero Don Juan Bartolomé Hovell para que iniciara las obras a fines de 1767, con el aval de los entonces alcaldes del Cabildo, don Vicente Azcuenaga y Don Manual Basavilbaso, aunque lo mismo no fuera tratado en acuerdo capitular. Una vez avanzadas las mismas, y viendo que era necesario contar con ciertos fondos para finalizarlas, el proyecto fue presentado al Cabildo para que colaborase con sus costos. Es así que el 18 de febrero de 1768 los alcaldes, don Joseph Lezica y don Martín Sarratea, junto con el Procurador General -don Manuel Basavilbaso- y el cuerpo de regidores, acordaron -para finalizar las mismas- implementar el derecho sobre

\footnotetext{
dificultaba señalar un límite claro entre el mismo y la traza, la pobre calidad del agua y la imposibilidad de organizar la deposición de las basuras, la existencia de numerosos "huecos" en las calles que se volvían espacios propicios para cometer "delitos y maldades", la mala calidad de las construcciones, aun de aquellas destinadas a realzar el poder tanto terrenal como religioso (como por ejemplo la Catedral y el Cabildo), entre otras problemáticas urbanas que sufría Buenos Aires en su funcionamiento cotidiano.

6 Por ejemplo, en un auto dictado el 12 de noviembre de 1766 el gobernador amenaza con una multa de 500 pesos a los capitulares, por no informarle sobre el contenido de los acuerdos celebrados desde su llegada al gobierno instándolos además a que se le avise con anterioridad, de modo de poder concurrir. (AGN -A- BANDOS: folio 108). Por otro lado y durante el mismo año, Bucareli obliga a los miembros del Cabildo a entregar el libro de acuerdos (que por privilegio del ayuntamiento se consideraba secreto) a los oficiales de la Real Hacienda al considerar que los aquellos intentaban comprometer el cobro de alcabalas. Todas estas cuestiones fueron resistidas, aunque sin éxito, por los miembros del Cabildo. (AECBAb, 1927, p. 445-446, 446-450, 450-452).

7 Esta reseña es el producto de la lectura y análisis bibliográfico y de los diversos corpus documentales ya citados.
} 
las cuadras del ejido concedido por Su Majestad, solicitando informes de los costos totales. En este punto no queda del todo claro, si la aprobación dependía de los costos o si el pedido de los mismos se realizaba solo a título informativo. Lo cierto es que una vez que el ingeniero Hovell los presentó a mediados de marzo, se desataron las controversias al interior del cuerpo capitular y la mayoría de los regidores se posicionó contra la idea de financiar las obras con el impuesto del ejido, logrando finalmente paralizar las mismas, utilizando para ello como argumento central los reclamos efectuados por los habitantes de la bajada del río cuyas casas habían sido o estaban siendo demolidas (AECBAb, 1927, p. 618628).

Los debates en general, giraron en torno a la conceptualización de lo que se consideraba o no una "obra pública", de las necesidades concretas de la ciudad, la escasez de propios, la defensa militar del fuerte, la existencia de damnificados y el respeto o no a la autoridad gubernativa, entre otras cuestiones. A lo largo del año, las discusiones fueron creciendo, junto con los argumentos tanto a favor como en contra, frente a la imposibilidad de lograr algún tipo de acuerdo y a la ausencia del gobernador que se hallaba en las provincias del Uruguay finalizando la expulsión de los jesuitas. Su teniente general, don Juan Manuel de Labarden, quien había quedado a cargo del gobierno, fue un ferviente defensor tanto del proyecto como de la autoridad de Bucareli y sucesivamente instigó a los capitulares a continuar con las obras, haciendo oídos sordos a los argumentos por ellos presentados. Por otro lado don Vicente de Azcuenaga supervisaba y financiaba de su propio caudal el desarrollo de las mismas, a la espera de ser retribuido. Finalmente y a pesar de las presiones a las que fueron sometidos los regidores de parte de Labarden, se ordenó la suspensión de las obras por decisión de la mayoría del cuerpo capitular, y se iniciaron acciones frente al Consejo de Indias para que determinase la validez o no de las mismas. Sin embargo, en 1770 el conflicto fue reavivado cuando Azcuenaga solicitó al gobernador que se le retribuyeran los costos que él mismo había suplido. Bucareli ordenó al Cabildo que se hiciera cargo de los mismos, a lo que el cuerpo capitular opuso resistencia. Nuevamente el conflicto escaló más allá del marco del proyecto concreto y Bucareli avanzó sobre ciertas prerrogativas del Cabildo como forma de presión y represalia. ${ }^{8}$ Finalmente el asunto fue dirimido en Madrid, donde el Consejo de Indias dictaminó que no estaba dentro de las capacidades del gobernador financiar las obras con el derecho sobre el ejido otorgado por Su Majestad, aunque no gravaba su conducta, ya que consideraban que había actuado con la anuencia del Cabildo -en particular en relación al acuerdo celebrado el 18 de febrero de 1768.

$\mathrm{Al}$ analizar los argumentos y las posiciones de los actores intervinientes, observamos la conformación de dos facciones. Aquellos que estaban a favor de Bucareli y de su teniente

8 Por ejemplo; no aprobó las elecciones capitulares para dicho año, prohibió que se llamase a acuerdos por medio del tradicional toque de la campana, multó a los capitulares y encarceló a los alcaldes. En: (DOC Y PLANOS, 1910, p. 190-197). 
general, formaban parte de los clanes $^{9}$ de comerciantes mayoristas más poderosos de la ciudad (Basavilbaso, Lezica, Azcuenaga), mientras que los regidores que se oponían formaban parte de las capas medias y en general se dedicaban al comercio minorista. En este sentido podemos intuir que existieron, como telón de fondo a las disputas argumentales razones y objetivos tanto políticos como económicos, tema que fue abordado en otros trabajos (SALVADORES, 1931; SIDY, 2012), como ser, el interés por lograr en control sobre la recaudación del impuesto del ejido y la defensa de la autonomía política del ayuntamiento frente a los avances centralizadores de los funcionarios borbónicos. Sin embargo, nuestro interés aquí radica en comprender cuáles eran las matrices ideológicas en las que se sustentaban los proyectos urbanos de Bucareli y en qué sentido los mismos podían afectar al funcionamiento tradicional de la ciudad en sus diversos planos de modo que se desatara una resistencia tan sistemática. En este sentido, en los siguientes apartados indagaremos en los diversos nudos argumentales que los actores involucrados fueron desarrollando para defender sus propuestas.

\section{Argumentos a favor de las obras}

Entre 1767 y 1770 las disputas argumentales en torno al proyecto de "las bajadas del río" fueron cobrando diversos matices, en la medida en que se fue haciendo necesario, ya fuera defender el proyecto como condenarlo. En este sentido, los partidarios de las obras fueron sumando argumentos en su defensa a medida que la oposición crecía.

Sin embargo, en un primer momento, la propuesta tenía como propósitos centrales la "comodidad, el lucimiento" y "la facilidad del giro del comercio del río que padece muchos inconvenientes por razón de los pantanos que en el tiempo de lluvias dificulta el tránsito al Riachuelo y barracas con grave perjuicio del común" (AECBAb, 1927, p. 587-589). La idea de proporcionar un ámbito abierto para el desahogo y la diversión de los porteños, que a su vez embelleciera el espacio de la ciudad estaba en consonancia con los nuevos planteos urbanísticos europeos que pretendían una incorporación de la naturaleza en la vida cotidiana ${ }^{10}$ que permitiera una cierta exteriorización del ocio y de la recreación que hiciera posible un mayor control de las actividades de la población de parte de las autoridades reales y era allí donde radicaba su utilidad. Así lo entendía Labarden:

9Tomamos la noción de "clan" de los trabajos de Socolow, quien sostiene que: "[...] los lazos de consanguinidad y los lazos políticos producían clanes de mercaderes que, aunque no formaran una sociedad concreta, eran leales entre si y les interesaba la prosperidad del otro[...]". (SOCOLOW, 1991, p. 63)

10 Ejemplo de esto es la construcción del Paseo del Prado en Madrid cuyos trabajos se iniciaron en 1763. (PINTO CRESPO; MADRAZO MADRAZO, 1995) 
Su hermosura y comodidad todos la atestiguan pues la disfrutan concurriendo por las tardes especialmente los días festivos toda clase de gentes a gozar de aquel recreo. [...] es una obra que VE ha mandado hacer en beneficio del público, y no para llevársela a su casa: y es una terquedad mal considerada el que por lo mismo que VE se ha empeñado en que la ciudad tenga esta utilidad, adorno, desahogo y diversión y de que raro será el que no goza se le estén formando oposiciones (DOC Y PLANOS, 1910, p. 267).

Por otro lado, podemos observar un interés por racionalizar la circulación en la ciudad, promoviendo la creación de accesos directos desde el Riachuelo hacia el fuerte y la plaza, facilitando así el comercio. Al analizar los proyectos de reconstrucción de la ciudad de Lima luego del terremoto de 1746, Walker (2008) observa como parte del ideario iluminista, los intentos de los funcionarios borbónicos por lograr que las calles condujeran al centro simbólico del poder, de modo que se lograse una circulación fluida de bienes y personas que favoreciera tanto el control social y el económico como la recolección de los impuestos. Durante el proceso llevado a cabo ante el Consejo de Indias, los defensores de las obras, relataron sucesivamente los beneficios que las mismas conllevaron para el abasto de la ciudad, principalmente durante el invierno, cuando las lluvias volvían intransitables los antiguos caminos. En su declaración al Consejo, Vicente Azcuenaga, superintendente de las obras, declaraba que:

[...] las tropas de carretas que vienen de las provincias de arriba y las del tráfico de esta ciudad, por serles más cómoda la entrada en la plaza, evitando las vueltas de las calles y los embarazos que muchas veces, suelen encontrar en ellas, que las suelen hacer de tener y principalmente en el invierno pasado, habiéndose puesto las calles intransitables, no tenían las carretas del abasto y las que vienen de afuera otra entrada y se sintió y reconoció bien la utilidad de esta obra pues mediante ella se experimentó el que no padeciese la ciudad las carestías (DOC Y PLANOS, 1910, p. 265-266).

Sin embargo, cuando aparecieron las oposiciones tanto al proyecto, como a la procedencia de los fondos con los cuales el mismo debía llevarse a cabo, los argumentos a favor cobraron otros matices. Por un lado, y sobre todo en la voz del teniente general don Juan Manuel de Labarden, se enfatizó, entre otras cosas, en la necesidad de lograr una cierta sujeción de parte del Cabildo hacia el representante del poder real, en este caso el gobernador Bucareli. Es así, que en sus dictámenes aparecían constantes alusiones a la improcedencia del accionar de los regidores, en los que advertía que: 
Estas controversias no son correspondiendo a la madurez con que deben obrar los Cabildos ni al superior se le ha de estar haciendo que firme decretos contrarios [...] en facilitar esto, así en lo que se debe poner el celo y no en arbitrar medios de que la cabeza débilmente siga, las inclinaciones o ideas de los miembros (AECBAb, 1927, p. 661).

Aparecía aquí la diferencia entre el lugar que ocupaban -para el teniente- dentro del gobierno político de la ciudad el gobernador y el Cabildo en tanto cuerpo que debía seguir los dictámenes de su superior. Sin embargo, tal como advierte Agüero (2005), al reflexionar sobre el funcionamiento municipal en el Antiguo Régimen, la forma de representación corporativa de la sociedad conjugaba tanto la unidad totalizante como su organización jerárquica y la diversidad particularista derivada de la conservación de la identidad de cada una de las partes. La misma metáfora organicista, que imponía la necesidad de que los miembros estuvieran dotados de una cabeza, hacía posible que los cuerpos, más allá de los lazos de subordinación, mantuviesen su identidad y sus capacidades propias. Por estas razones, los impulsos centralizadores que se imponían desde España y los márgenes de autonomía adquiridos por los poderes locales en las colonias, en este caso el Cabildo porteño, entraron sucesivamente en tensión. ${ }^{11}$

En segundo lugar, los defensores de las obras -entre ellos, principalmente Labarden- se orientaron a señalar el valor defensivo que las mismas representaban, ya que la finalización en barrancas de las calles orientadas al río, habría estado comprometiendo la posibilidad de fuego en caso sucederse un ataque: "[...] era una deformidad perjudicial a la fortaleza porque la artillería no estaba libre pues si se tiraba con bala o era necesario elevarla mucho, porque no se enterrase en las barrancas" (DOC Y PLANOS, 1910, p. 263).

[...] el fundamento de esta obra no es como quiera un mero adorno de la ciudad es una obra de las más necesarias urgentes y útiles pues a dimanado de haber reconocido el ingeniero que la fortaleza estaba con su artillería embarazada sin poder jugarla en caso de necesidad [...] obra no se puede disputar porque es esencialísima para el resguardo y defensa de la ciudad (AECBAb, 1927, p. 665).

Cabe señalar que los proyectos reformistas en las colonias americanas cobraron impulso a partir de la toma de La Habana y Manila por los ingleses en 1762. Estos sucesos visibilizaron la necesidad de racionalizar y modernizar los territorios de la monarquía como único medio de potenciarlos y conservarlos frente a las agresiones foráneas, reforzando los

11 La historiografía clásica, sostuvo que a lo largo del siglo XVIII los Cabildos fueron perdiendo la autonomía de la que gozaban, a causa de las políticas cada vez más centralistas de la corona borbónica (ZORRAQUIN BECÚ, 1952). Sin embargo, Agüero (2005) advierte que durante este siglo persistían los principios que naturalizaban a la ciudad y a su gobierno, con sus implicancias en términos de autogestión, la autonomía seguía siendo entendida como consecuencia de la naturaleza misma de la ciudad. 
dispositivos de defensa en cada área. En este sentido, podemos pensar que los argumentos defensivos, que por otra parte se hacen presentes una vez desatado el conflicto y no en sus inicios, aparecen como elementos de persuasión hacia el Cabildo y en vistas a las presentaciones ante el Consejo de Indias, pero no necesariamente como la motivación principal para realizar las obras, como insisten en proponer el teniente general Labarden y el ingeniero Hovell. Principalmente porque dichas razones se dan en conjunción con los reclamos de los habitantes de las barrancas a quienes, por orden del gobernador, se les habían derribado sus casas para la continuación de las obras. Como ya mencionamos fue este, el punto que definió a la mayoría de los regidores a decidir la suspensión de las tareas.

Los defensores de las obras, sin embargo, sostuvieron la necesidad de llevar a cabo los derribos de las casas, no solo por las razones defensivas arriba explicadas, sino también por la irregularidad que dichas construcciones representaban para el aspecto y racionalidad de la ciudad. En principio se sostuvo que:

[...] aquellos terrenos no son traza de ciudad ni deberían haberse poblado y así ha sido una mala tolerancia y algún día había de llegar el caso de esta ruina además de que la indecencia y desigualdad de aquellas zanjas ejecutaba a su composición (AECBAb, 1927, p. 665).

El teniente general señalaba la irregularidad tanto de las construcciones como de la posesión, por parte de particulares de terrenos fuera de la traza, es decir en el ejido, más allá de que, como ya mencionamos, esta cuestión ya había sido dirimida, cuando Su Majestad otorgó el derecho a cobrar un impuesto sobre estos terrenos. De todos modos, no deja de ser interesante observar cómo este funcionario sigue apelando al plateo inicial de la ciudad colonial, según el cual dichos terrenos nunca deberían haberse cedido para ocupación particular. Sobre este tema el ingeniero Hovell advertía que:

[...] era necesario también quitar aquellas casitas que estaban situadas irregularmente en el declivo de la barranca que todas eran de poca importancia y parecía se habían puesto arbitrariamente porque las calles terminaban en una que iba de norte para sur desde el fuerte la cual estaba intransitable para carretas y solamente a pie o a caballo se podía andar por ellas uno a uno y para dar curso a toda la ciudad y a las bajadas era preciso igualarlas (DOC Y PLANOS, 1910, p. 263).

Por lo expuesto, podemos deducir razones que sin entrar en contradicción con la necesidad de generar espacios de recreación que fueran a su vez fácilmente controlables por un lado y facilitar el tránsito del comercio por el otro, estaban estrechamente vinculadas a 
los propósitos del ideario borbónico. Francisco de Solano (1990) explica que a partir de mediados del siglo XVIII la corona buscó "perfeccionar" la ciudad hispanoamericana con la implementación de significativos cambios físicos por medio de los cuales sería posible ir transfigurando su aspecto inacabado por uno más homogéneo y equilibrado. La "ciudad ilustrada", implicaba idealmente una traza pulcra y edificios simétricamente dispuestos. Para el caso de Lima, Ramón indica que:

La reorganización de la ciudad bajo parámetros cartesianos y la construcción de suntuosos edificios oficiales de estilo neoclásico eran concomitantes con la reorganización social a intramuros y debían transmitir un mensaje unívoco que contribuyera a civilizar a sus habitantes (RAMÓN, 1999, p. 296).

Sin embargo, De Solano advierte que dichas transformaciones no fueron el resultado de un proceso armonioso ni respondieron únicamente al impulso metropolitano, si no que coexistieron otros causantes como ser, el crecimiento demográfico y la inmigración descontrolada, "[...] al trazado geométrico y ejemplar del siglo XVI se van añadiendo torpes barrios marginales autoconstruidos por sus habitantes, en donde la miseria se acompaña de una profunda peligrosidad motivo de preocupación para las autoridades municipales" (DE SOLANO, 1990, p. 93).

Ante las problemáticas derivadas del aumento de la población las autoridades coloniales fueron elaborando estrategias para disminuir el número de aquellas personas que eran consideradas como indeseables, o por lo menos para organizar el espacio de la ciudad de manera tal que las mismas no incidieran en el aspecto que se esperaba de una ciudad capital. Como corolario de estas intenciones vale señalar también las declaraciones realizadas por Vicente de Azcuenaga y Manuel Basavilbaso ante el Consejo de Indias, en las cuales señalaban que: "al mismo tiempo era un defecto muy notable para la ciudad tener la principal parte de su frente llena de barrancones y zanjas propias para encubrir delitos..." $y$ “...concurriendo también el poderse celar con menos dificultad el contrabando y las ofensas de dios que proporcionaba por aquellas partes la situación de las barrancas y cercos de tunas..." (DOC Y PLANOS, 1910, p. 266, 267).

Es decir que las obras además estarían, por un lado evitando la acumulación de basuras e "inmundicias" en dichas zanjas que podrían propagar enfermedades y por el otro sirviendo para contener los conflictos provocados por las dificultades que las autoridades locales advertían a la hora de contener los delitos y aprehender a los culpables. ${ }^{12}$ En realidad

12A lo largo de los años, se venían reiterando los bandos de gobierno en los cuales se ordenaba a los dueños de los "huecos" vacios dentro de la ciudad que o bien construyeran en ellos o los vendieran, ya que representaban espacios marginales, propicios para la transmisión de enfermedades y en los que se cometían "ofensas contra dios" imposibles de controlar (por ejemplo ver: AGN-A-BANDOS: folios: 7-8, 9-8-10-2 f. 38 y 91-92). 
se trataba también de una puja entre las jurisdicciones del Cabildo y de los gobernadores, ya que si bien eran los primeros los encargados de la justicia en primera instancia y por ende de controlar la aprehensión de los culpables, correspondía a los gobernadores cuidar del llamado "ramo de policía" cumpliendo las leyes y ordenanzas, establecidas para el buen gobierno de la ciudad. Se trataba de un concepto íntimamente vinculado a la vida urbana, el buen orden, la disciplina pública y el aseo (SAMUDIO, 2009). Con la llegada de los borbones a la corona española se produjo un avance en la ciencia de policía, considerada una disciplina calve para la gobernabilidad. Es así que los funcionarios borbónicos, entre los que estaba Bucareli, buscaron contrarrestar la incidencia de las autoridades locales en estos asuntos asumiendo su responsabilidad. En este punto el Consejo de Indias acabó avalando la decisión del gobernador de emprender las obras al señalar que "[...] además de aseo y hermosura involucra al ramo de policía que compete privativamente al gobernador" (DOC Y PLANOS, 1910, p. 127).

En las presentaciones al Consejo de Indias aparecieron, en la voz del propio Bucareli, otras cuestiones que ubicaban a las obras proyectadas y a él mismo, dentro de los idearios borbónicos. En primer término el gobernador sostenía que la obra de las casas capitulares: "es bastante suntuosa y hecha a todo costo" (DOC Y PLANO, 1910, p. 125) lo que se correspondería con la ostentación propia del estilo barroco en contraposición al estilo neoclásico planteado por los borbones, desde el cual se proponía una cierta austeridad como contestación al modelo social anteriormente nombrado (HERNANDO, 1989, p. 15-19).

Por otro lado, al reconocer que el nudo del conflicto se encontraba en el uso de los fondos otorgados por Su Majestad, el gobernador se dedicó a presentar y revisar las cuentas del Cabildo porteño advirtiendo su mala administración: "[...] con que sino se extinguen esas deudas es cierto que dimana de la mala administración que hay en las rentas [...] se vendrá en claro conocimiento de que están debiendo porque quieren" (DOC Y PLANOS, 1910, p. 125). Lo que es comprensible si consideramos que una de las intenciones fundamentales de los reformadores borbónicos consistía en sanear las finanzas americanas de manera que se fortaleciera la economía española. El gobernador concluía que probablemente la oposición se avivara por el interés por manejar los nuevos fondos que entrarían al erario público, aunque apuntaba sus sospechas hacia el principal opositor a las obras:

[...] don Gregorio Ramos Mejía [...] ha descubierto una quiebra de muchos miles que no alcanzan a pagar sus bienes embargados todos y puestos en almonedas que es claro para atajar este suceso le interesaba manejar el ramo y que este ha sido el origen y principal fundamento de estas irregulares contradicciones disfrazadas con el velo de que son hombres que saben hacer frente al que gobierna (DOC Y PLANOS, 1910, p. 126). 
Si bien como ya mencionamos, no cuestionamos la posibilidad de que el gobernador hubiera acertado en descubrir las razones y/o los objetivos concretos que llevaron a los regidores encabezados por Ramos Mejía a presentar una férrea oposición a sus proyectos, consideramos que en los argumentos presentados por ellos contra la realización de las obras se despliegan -al igual que en los testimonios a favor- ciertas nociones en relación a la forma de proyectar desde el ámbito gubernativo la vida urbana y por ende las obras que le eran necesarias.

\section{Los argumentos en contra}

Luego de presentados los costos de las obras al Cabildo, en marzo de 1768, se desarrolló - como ya fue mencionado- una encendida oposición de parte de algunos de los regidores, entre los que se destacó Gregorio Ramos Mejía ${ }^{13}$. Los capitulares, defendieron su derecho a manejar y disponer de los fondos de la ciudad con la autonomía acostumbrada, a pesar de los esfuerzos de Bucareli y de su teniente general, por ceñirlos a sus designios. En este sentido y con respecto a los argumentos brindados por Labarden en relación a la pretendida inobediencia y maltrato otorgado por parte de los regidores al gobernador, los primeros advertían que:

[...] las leyes y establecimientos de las ciudades de estos reinos que no conceden la administración y distribución de los propios y arbitrios a otro que el ayuntamiento, [...] siendo por otra parte cierto que consiguientemente a estado este Cabildo en la pacifica posesión de disponer de ellos, rever y tomar las cuentas respectivas y con absoluta independencia de los señores gobernadores (DOC Y PLANOS, 1910, p. 229).

Más allá de las posibles estrategias legales que hayan utilizado los regidores para impedir el uso del derecho sobre el ejido para la Alameda ${ }^{14}$ así como el avance sobre sus prerrogativas tradicionales por parte de los funcionarios borbónicos, creemos que dentro de los testimonios que ellos brindaron es posible entrever una forma de pensar a la ciudad y a

13 Comerciante llegado a Buenos Aires en 1749, aparentemente sin contactos de especial envergadura. En 1761 entra en la orden tercera de San Francisco. En 1766 se lo nombra mayordomo de la ciudad. Finalmente en octubre de ese mismo año accede a la compra del cargo de regidor. A partir de allí inició una carrera que lo tuvo durante casi cuarenta años como miembro del Cabildo. Como comerciante al por menor, nunca logró un éxito notable, viviendo por momentos importantes estrecheces económicas. Aparentemente fue un importante defensor de las atribuciones del Cabildo como organismo de gobierno de la ciudad (LEVAGGI, 1983).

14 Como por ejemplo cuando se hace referencia a los designios y el respeto debido a Su Majestad: "que por reales leyes nos es prohibido el mandar hacer unas [obras públicas] sin particular licencia de Su Majestad y concedido el hacer otras sin nuevo permiso", "Pues dice se destina este ramo a acabar las casas capitulares en primer lugar, y siendo como va dicho procedido el debito de dicha obra, parece será ir contra lo mandado por Su Majestad" (AECBAb, 1927, p. 622). 
las funciones de quienes están a cargo de su gobierno, distinta a la propuesta por Bucareli, en tanto representante borbónico, en particular en lo relativo a qué se entendería por una "obra pública".

Por un lado, Gregorio Ramos Mejía contaba con una ventaja sustancial por sobre el gobernador que utilizó como base de sus argumentaciones y que radicaba en el profundo conocimiento que tenía, tanto en relación las necesidades estructurales de la ciudad como a las que observaba para el comercio al por menor dentro de la misma, actividad a la que él mismo se dedicaba.

En primer lugar, declaraba que los propios de la ciudad eran escasos y contingentes, mientras que la mayor parte de sus gastos tenían el carácter de fijos, con lo cual se volvía muy dificultoso cubrir sus deudas y finalizar las casas capitulares. En este sentido, se detenía a detallar el estado de las mismas advirtiendo que, debido a la forma en que estaban edificadas al momento, no se podía cumplir con ciertas formalidades propias del sistema socio estamental barroco característico del Antiguo Régimen, como ser que los reos estuvieran separados de acuerdo a su condición y estado (AECBAb, 1927, p. 620).

Por otro lado, se detenía a detallar las obras que serían necesarias en la ciudad, con mayor urgencia que la Alameda en relación a la cual, insistían los capitulares, solo tenía por objetivos, "la policía, recreo y adorno [...] un paseo con alameda cuya amenidad y espacio a desembarazo de toda fábrica sirviese a la recreación y diversión del pueblo" (DOC Y PLANOS, 1910, p. 132). Por oposición a estos propósitos, que evidentemente consideraban menores, Ramos Mejía advertía que:

[...] la planta tan extensiva de esta ciudad y la mucha población pide tres plazas más, que cada una tenga los menos media cuadra, pues estando la plaza principal a la lengua del agua, no pueden los vecinos y moradores, principalmente los pobres, que son los que viven más distantes, sin gran comodidad, abastecerse del comestible diario [...] se necesitan hacer resguardos de corredores fijos o portátiles para resguardo de los vendedores y compradores -se necesitan unas casas para alhóndiga [...] para comodidad de los que venden ; y para evitar tantos regatones que hay para el trigo (AECBAb, 1927,p. 627).

Proponía además, que se comprase una chacra en el ejido para pastos comunes y abasto de la ciudad, hablaba del agua y del mal estado de las calles, lo que causaba zanjas y pozos que iban "perdiendo" las calles, proponiendo la contratación de un alarife asalariado que arreglase las corrientes que debían tener los caminos, así como también que se acarreasen piedras para cubrir las esquinas de manera que el agua no inundase las calles "y no se hagan pantanos cuya necesidad es tan notoria que no necesita mayor explicación" (AECBA, 1927, p. 626). 
A su vez, indicaba -no sin cierto histrionismo- que los terraplenes que el ingeniero Hovell se encontraba levantando en las barrancas, dificultaban el acceso al río de los más pobres:

[...] a dónde iran los aguateros por el agua cerrada por dicha muralla, la bajada del río? Los criados y criadas que cada uno por sus calles tenía bajada para traerla a dónde y por dónde ira? Los pobres y los que van cargados con sus bateas de ropa al río para lavar (pues en sus casas no lo pueden hacer sin mucho costo) dónde lo harán? (AECBAb, 1927, p. $627)$.

En definitiva, aducía que la Alameda era una obra posible de realizarse solo después de haberse resuelto las cuestiones por él mencionadas. A partir de sus propuestas, podemos notar un profundo interés de parte del regidor por fortalecer el comercio al interior de la traza de la ciudad, generando nuevas áreas para la compra y venta de productos de abasto a las que pudiera acceder la creciente población porteña dada su dispersión en el espacio de la ciudad, así como también, mejorar el tránsito al interior evitando la creación de zanjas e inundaciones en las calles, todas cuestiones más urgentes que un simple "paseo".

Cabe recordar, aunque Ramos Mejía no haga alusión al tema, que una de las funciones de las obras llevadas a cabo por Bucareli era la de facilitar el acceso a la plaza de las carretas con mercaderías provenientes de "las provincias de arriba", lo que en invierno se volvía impracticable debido a las lluvias. Es decir que, tenemos por un lado al gobernador intentando facilitar el acceso de mercaderías a la plaza y por el otro al regidor proponiendo obras que facilitarían el abasto en distintos puntos de la ciudad, ¿se trataba realmente de puntos de vista irreconciliables?, ¿o si lo pensamos en diferentes escalas se podía tratar de planteos complementarios?. Cabe advertir que las medidas propuestas beneficiaban a distintos tipos de comerciantes (mayoristas, en el caso de lo propuesto por Bucareli y minoristas en referencia a lo sugerido por Ramos Mejía) y en este sentido Socolow (1991) advierte, en cuanto a los comerciantes en general, que había escisiones dentro del grupo que estaban directamente determinadas por la escala de la actividad que cada uno desempeñaba. Dentro de cada uno de estos grupos existía -de acuerdo a la autora- un fuerte sentimiento de solidaridad y la percepción de posibles amenazas debidas a cambios de políticas, alentados por otro de los grupos - cabe señalar que los capitulares que bregaron por la alameda pertenecían al grupo de grandes mayoristas. ${ }^{15}$

Pero más allá de la influencia de estas solidaridades grupales a la hora de promover o no ciertas políticas urbanas, los regidores, encabezados por Ramos Mejía, a la hora de argumentar contra la Alameda, cuestionaron en sus testimonios la validez de dicha obra,

15 Vicente de Azcuenaga, Jose de Lezica, Manuel y Francisco Basavilbaso, quienes además estaban emparentados entre sí. 
discutiendo su pertinencia en tanto obra pública, en contraposición a sus propias propuestas, lo que nos permite entrever, por un lado la existencia de al menos dos formas de conceptualizar a lo público dentro de la ciudad que en este caso entraron en tensión.

Ya en un primer momento, Ramos Mejía había intentado que se convocase a dos asesores letrados para que determinasen si la propuesta de Bucareli podía o no considerarse como una obra pública. Si bien, este intento no prosperó, el regidor continuó con esta tendencia al sostener que: "[...] en esta palabra de obras públicas no debemos solo entender; edificios públicos, sino es todo aquello que sea tan a beneficio de él" (AECBAb, 1927, p. 597). Luego de indicar todas las obras que sería pertinente realizar con mayor urgencia que la Alameda, podemos ver en su testimonio, los objetivos concretos de las mismas:

[...] por la comodidad de los vendedores y compradores y por el aumento que resulta de los propios para las demás obras que necesitan [...] y del útil que dieren, con el tiempo todas estas obras, empedrarse todas las calles y aun profundizando la zanja, que circunvala lo principal de esta ciudad se puede hacer un canal por donde desagüen muchas de ellas todo lo propuesto que es tan conveniente a la ciudad como va dicho, (hecho por su orden) lo inutilizan las obras propuestas porque la Alameda, [...] que solo su costo ascenderá a una cantidad de pesos que en muchos años no se pueda acabar por no haber con que, a más del costo de las fajas de piedra que siquiera se necesitan por su plan, sin que de ellos esperen los propios del público ningún ingreso (AECBAb, 1927, p. $628)$.

Es decir que el regidor, consideraba como obra pública prioritaria a todo aquel emprendimiento que pudiese generar réditos monetarios, que a su vez fuesen útiles para emprender nuevas obras o para solventar los arreglos que la ciudad necesitaba. El paseo, como tal, se reconoce como un emprendimiento imposible tanto de financiarse a sí mismo, como de generar nuevos réditos, lo que vuelve su clasificación como obra pública cuestionable -o por lo menos pasible de ser pospuesta- a los ojos de los regidores que apoyaban a Ramos Mejía. Es en este sentido que, desestimando los objetivos defensivos del emprendimiento -dado que los veían como meras excusas-, sostuvieron ante el Consejo de Indias que se trataba de: “...unas obras voluntarias que por recreo y diversión había el gobernador emprendido por si" (DOC Y PLANOS, 1910, p. 254) y que solo generaba grandes pérdidas a los caudales públicos. Sus testimonios continuaban alegando la escasez de sus propios, así como la magnitud de sus deudas y obligaciones. Todas cuestiones que Bucareli no comprendió, o no quiso comprender, empeñado como estaba -según los regidores- en concluir con sus proyectos, lo que lo llevó finalmente en 1770, a multar y encarcelar a los regidores que se rehusaban a cubrir los costos de la obra. En este sentido los capitulares alegaban que: 
[...] el Cabildo es verdad interesa en que el aspecto de su ciudad sea el más ameno, espacioso y de recreo: pero más interesa sobre ser de justicia en contener a sus acreedores ínterin no puede desprenderse de ellos; en reedificar sus casas consistoriales y otras de abasto público: sus muros y fortalezas; y esto habiendo cumplido aquellos créditos. Que diría el mundo, o que dirían aquellos si divertida la ciudad y divertidos sus fondos en recreos, no cumpliese sus cargos públicos y de conciencia? (DOC Y PLANOS, 1910, p. 254).

Evidentemente y dadas las condiciones económicas de la ciudad de Buenos Aires, para el cuerpo capitular, la construcción de paseos y recreos no se correspondía con la noción de justicia, ni tenía validez en tanto obra pública. Se consideraba preciso que las mismas resultasen en réditos monetarios concretos, que permitieran un cierto desahogo para los propios del Cabildo, tradicionalmente exiguos.

\section{A Modo de Conclusión}

A lo largo de los dos últimos apartados hemos reseñado los principales argumentos elaborados ya fuera pare defender las obras como para condenarlas. Bucareli y sus seguidores, ofrecieron un amplio abanico de razones por las cuales las mismas eran consideradas necesarias. La creación de un espacio apto para la recreación controlada de todos los sectores de la sociedad, que a su vez eliminase los espacios propicios para esconder "delitos" y/o "inmundicias", el acondicionamiento de la bajada del río para el uso de la artillería en caso de ataque y la disposición de un camino directo desde el Riachuelo hacia la plaza eran las ventajas que percibían como evidentes para el mejor funcionamiento de los servicios urbanos. Por otro lado, cuestionaron la habilidad del Cabildo para administrar sus fondos, advirtieron sus sospechas en relación al manejo de los réditos provenientes del impuesto del ejido y sostuvieron la superioridad de la autoridad del gobernador respecto a la toma de decisiones en relación a las obras a llevarse a cabo en la ciudad.

Por su parte, los regidores que se opusieron a Bucareli buscaron en todo momento defender su derecho a manejar los propios de la ciudad de acuerdo a sus designios y no a aquellos que les eran impuestos, comprendiendo rápidamente que el principal objetivo de las obras emprendidas por Bucareli estaba vinculado a la recreación, el paseo y el aseo de la ciudad y no, como se sostuvo luego a la defensa de la misma. En este sentido, desestimaron los propósitos del gobernador, señalando con absoluta precisión y detalle las obras que consideraban urgentes y "precisas", por contraposición a aquellas a las que solo les cabía el apelativo de "decentes". Lo "preciso" en este caso, estaba vinculado al funcionamiento del 
comercio al interior de la ciudad, el arreglo y acondicionamiento de sus calles y calzadas, así como también a la elaboración de diversas obras que pudiesen producir réditos para el ayuntamiento.

Con respecto a los argumentos elaborados en cada caso, es importante diferenciar entre las estrategias discursivas a las que se apeló -cómo por ejemplo el énfasis puesto en la defensa a las intenciones de Bucareli por parte de Labarden, o las preguntas retóricas enunciadas por Ramos Mejía con respecto a los sectores bajos de la población-, los modelos, tanto de la ciudad como de su gobierno, que eran sostenidos por dichas estrategias y por otra parte cuáles eran los intereses que las diferentes posturas representaban. En relación a estos últimos si bien no ha sido el objetivo de este trabajo, cabe señalar como principal, el manejo efectivo de los fondos provenientes del impuesto sobre ejido, así como ciertas cuestiones políticas que lo mismo traía aparejadas, como ser, los propósitos de centralización por parte de Bucareli.

Con respecto a los modelos y/o representaciones que se dejan vislumbrar durante los debates, se vuelve evidente la puja entre dos formas distintas de concebir a la ciudad así como también diversos modos de comprender los deberes y prerrogativas de las autoridades políticas en relación al control de la vida urbana. Se trata de una disputa entre el nuevo ideario borbónico en relación al Estado como fuerza organizadora, tanto de los espacios como de los habitantes y la organización tradicional del gobierno colonial que garantizaba una cierta autonomía a los poderes locales en relación al control de los asuntos políticos y económicos de la ciudad.

Desde el ideario iluminista, los funcionarios reales buscaron reorientar las prácticas cotidianas de los habitantes de las ciudades de manera que se pudieran evitar el desarrollo de conflictos sociales y racionalizar la administración de cargas e impuestos. En este sentido, se propusieron la creación de paseos y plazas de toros en distintas ciudades de América. Perez Cantó señala, que en la ciudad de Lima, con la construcción de la plaza de toros en 1768, los Borbones buscaron procurar desde el gobierno diversiones públicas para mantener al pueblo alegre y evitar los inconvenientes y los vicios que se ocasionaban habitualmente, por el ocio y las juntas privadas cuando en las ciudades no había estos entretenimientos y recreos (PEREZ CANTÓ, 1985, p. 28). Es decir, externalizar el ocio, darle la visibilidad necesaria para facilitar su control de parte de las autoridades.

Con estas y otras reformas, tendientes a lograr un conocimiento acabado de las características de la población - vale señalar que la primera medida ordenada por Bucareli al Cabildo porteño fue la de realizar un exhaustivo empadronamiento de todos los estantes y habitantes de la ciudad, sin excepción de sexos ni edades-(AECBAb, 1927, p. 412-414) el proyecto borbónico buscaba contener la retórica barroca, reorganizar las vías públicas de las ciudades y tomar su control; "el proyecto social borbónico se concentraba en el control de los espacios públicos y la homogeneización del lenguaje y las prácticas culturales” (WALKER, 
2007, p. 108). Consideramos que el proyecto de la alameda de Buenos Aires, así como los argumentos que se utilizaron en su defensa estaban orientados en esta dirección política.

Sin embargo, se encontró con una dura resistencia de parte del poder local que no estaba dispuesto a abandonar la posibilidad de acceder a réditos económicos concretos, en beneficio de un ordenamiento social que a largo plazo, pudiese llegar a beneficiarlos. No obstante, esto no implicaba que los regidores no tuvieran en mente a su vez un proyecto urbano concreto, un modelo de ciudad -tanto en lo espacial como en lo político- al cual apuntaban. Las propuestas con las cuales rebatieron los argumentos del gobernador, tenían como eje el mejoramiento de las condiciones del comercio y del tránsito al interior de la ciudad, así como también, una encendida defensa de sus prerrogativas en tanto institución a cargo del gobierno urbano. Vale recordar que en los memoriales enviados al Consejo de Indias, el Cabildo señala que la obra "[...] fue determinada y aun empezada a verificar sin noticia alguna del Ilustre Cabildo como era necesario una vez que se conceptuaba pública y se premeditaba costear de los propios de la ciudad a quien solo toca librar en ellos" (DOC Y PLANOS, 1910, p. 226). En este sentido podemos intuir que Bucareli, imbuido como estaba de los preceptos del centralismo borbónico, desestimó las capacidades del Cabildo en tanto institución de poder local, a la hora de defender su autonomía y su poder de decisión sobre el uso y destino de los propios de la ciudad.

Como corolario, vale señalar el rol del Consejo de Indias en la resolución de este conflicto para comprender a su vez, el grado de compromiso concreto que el poder real demostró a la hora de implementar las reformas urbanas que él mismo proponía. Como ya mencionamos, finalmente se decidió la suspensión de las obras y la devolución de los fondos recaudados a partir del derecho sobre el ejido al Cabildo. Sostuvieron que Bucareli no debió haber intentado utilizar dichos fondos, ya que por cédula real se ordenaba claramente que su destino fuera la finalización de las casas capitulares. Sin embargo, no se castigaba el accionar del gobernador, ya que se consideraba que el mismo había actuado con la anuencia del Cabildo y que las obras propuestas entraban dentro de la categoría de "necesarias". Es decir, lo que se considera erróneo en el accionar de Bucareli, no era la ejecución de las obras en sí mismas sino la procedencia de los fondos con los que pretendía realizarlas, aunque tampoco se insistía desde el Consejo de Indias para que se implementase algún medio alternativo que permitiese finalizar estas obras que ellos mismos entendían como "muy necesarias".

La determinación de la corona española, frente al conflicto, no atentaba finalmente contra la autonomía del Cabildo ni contra su autoridad en relación al destino de los fondos de la ciudad, ni tampoco sentaba las bases para determinar un cambio significativo en torno a las características que debía tener una "obra pública" en función a los planteos neoclásicos y/o iluministas. Lo que nos permite pensar que reformismo e ilustración, no se correspondían entre sí como hechos históricos homogéneos y relacionados 
automáticamente, sino que se trató de una relación plagada de fisuras y contradicciones vinculadas a los distintos elementos y variables que componían las realidades americanas, así como también a la difícil posición de la monarquía española en el contexto internacional de la época. En este sentido, Walker nos advierte que: "Las reformas urbanas efectivas eran costosas y los Borbones en general no estaban dispuestos a invertir" (WALKER, 2007, p. 115), ni a sufrir los costos políticos derivados de la oposición de las elites locales. De este modo, las reformas urbanas, que pretendían racionalizar los espacios compartidos de la ciudad sufrieron contradicciones y retrocesos y no lograron alterar - al menos en lo inmediato- los principios y los valores tradicionales en los cuales se asentaba el gobierno urbano colonial.

\section{Fuentes}

Archivo general de la nación Argentina (A.G.N -A-). Bandos de los Gobernadores del Río de la Plata, Sala IX, gobierno colonial. Ubicación: 9-8-10-1: 1741-1752/9-8-10-2: 1753-1763 / 9-8-10-3 1763-1777.

Archivo General de la Nación (1930). Acuerdos del extinguido Cabildo de Buenos Aires a (AECBA a) Serie II Tomo IX Libros XXVI - XXX 1751-1763, Buenos Aires.

Archivo General de la Nación (1927). Acuerdos del extinguido Cabildo de Buenos Aires b. (AECBA b) Serie III Tomo III Libros XXXIII - XXXIV - XXXV (1762-1768) Buenos Aires.

Documentos y planos relativos al período edilicio colonial de la ciudad de Buenos Aires 1910. Tomo II. Casa capitular y cárcel, régimen policial, oficios, obras públicas. Municipalidad de Buenos Aires, Peuser.

\section{Referencia}

AGÜERO, Alejandro. Ciudad y poder político en el Antiguo Régimen. La tradición castellana. Cuadernos de Historia. Córdoba, n. 15, p. 127-163, 2005.

DE SOLANO, Francisco. Ciudades hispanoamericanas y pueblos de indios. Madrid: Biblioteca de historia de América, 1990.

FAVELUKES, Graciela. Orden simbólico y orden práctico: operaciones gráficas sobre Buenos Aires. In: IMÁGENES Y LENGUAJES CARTOGRÁFICOS EN LAS REPRESENTACIONES DEL ESPACIO Y DEL TIEMPO/SIMPOSIO IBEROAMERICANO DE HISTORIA DE LA 
CARTOGRAFÍA, 2006, Buenos Aires. Anales... Buenos Aires: Instituto de geografía, 2006. p. 47-61.

HERNANDO, Javier. Arquitectura en España, 1770-1900. Madrid: Cátedra, 1989.

LEVAGGI, Abelardo. Gregorio Ramos Mejía, regidor y archivero del Cabildo de Buenos Aires (1725-1808). Su informe sobre el origen, variaciones y regulaciones de los oficios concejiles primera parte-. Separata de Investigaciones y Ensayos. Buenos Aires, n. 30, p. 367-399,1983.

MORSE, Richard. El desarrollo urbano de la Hispanoamérica colonial. In: LOCKHART, James; SANCHEZ-ALBORNOZ, Nicolas. América Latina en la época colonial.2. ed. Barcelona: Crítica, 2003. t. 2. p. 273-306.

PÉREZ CANTÓ, María Pilar. Lima en el siglo XVIII: estudio socioeconómico. Madrid: Universidad Autónoma de Madrid, 1985.

PINTO CRESPO Virgilio; MADRAZO MADRAZO, Santos. Madrid, atlas histórico de la ciudad: siglos IX-XIX. 2. ed. Madrid: Centro de documentación y estudios para la historia de Madrid, Lunwerg, 1995.

RAMÓN, Gabriel. Urbe y orden: evidencias del reformismo borbónico en el tejido limeño. In: GODOY, Scarlett O'Phelan. El Perú en el siglo XVIII: la era borbónica. Lima: Pontificia Universidad católica del Perú. Instituto Riva-Agüero. 1999. p. 295-324.

RÍPODAS ARDANAZ, Daisy. Los servicios urbanos en las indias durante el siglo XVIII. Separata de Temas de Historia Argentina y Americana, Buenos Aires, n. 2, p. 187-208, 2003.

SALVADORES, Antonio. Un proyecto del gobernador Bucareli para embellecer Buenos Aires: la calle de la barranca y el paseo de la alameda. Boletín del instituto de investigaciones históricas, Buenos Aires, año 10, n. 49/50, p. 40-56. 1931.

SAMUDIO, Edda. Los bandos de buen gobierno y ordenamiento de la vida urbana en Mérida, Venezuela: 1770-1810. In: GARCÉS, Eduardo Kingman. Historia social urbana: espacios y flujos. Quito: FLACSO, 2009. p: 173-186.

SIDY, Bettina. Las relaciones entre el Cabildo de Buenos Aires y el gobernador Bucareli: vínculos familiares, tensiones internas e intereses en disputa (1766-1768). Revista del archivo histórico municipal de Córdoba, Córdoba, n. 7. 2012 en prensa.

SOCOLOW, Susan. Los mercaderes del Buenos Aires virreinal: familia y comercio. Buenos Aires: De la Flor, 1991. 


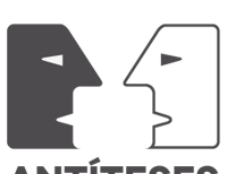

ANTÍTESES

TAU ANZOATEGUI, Victor. La costumbre en el siglo XVIII. Doctrina jurídica y praxis rioplatense a través de los Cabildos. Revista de la Facultad de Derecho de México IV Congreso Internacional de Historia del Derecho Indiano, México, n. 101/102, p. 671-725, 1976.

WALKER, Charles. ¿Civilizar o controlar?: el impacto duradero de las reformas urbanas de los Borbones. In: BERRÚ, José Enrique Briceño. Cultura política en los Andes (1750-1950). Lima: Universidad nacional de San Marcos, 2007. p. 105-129.

WALKER, Charles. Shaky colonialismo: the 1746 earthquake in Lima, Peru, and its long aftermath. Londres: Duke University Press, 2008.

ZORRAQUIN BECÚ, Ricardo. La organización judicial argentina en el período hispano. Buenos Aires: Biblioteca de la sociedad de historia argentina, 1952. 